\title{
Leiomyosarcoma Arising in the Pancreatic Duct: A Case Report and Review of the Current Literature
}

\author{
Nicole D. Riddle, ${ }^{1}$ Brian C. Quigley, ${ }^{1}$ Irwin Browarsky, ${ }^{1}$ and Marilyn M. Bui ${ }^{1,2}$ \\ ${ }^{1}$ Department of Pathology and Cell Biology, University of South Florida College of Medicine, 12901 Bruce B. Downs Blvd, \\ MDC 11, Tampa, FL 33612, USA \\ ${ }^{2}$ Departments of Anatomic Pathology and Sarcoma, H. Lee Moffitt Cancer Center \& Research Institute, Tampa, FL 33612, USA
}

Correspondence should be addressed to Nicole D. Riddle, ndemers@health.usf.edu

Received 4 February 2010; Accepted 12 April 2010

Academic Editor: Klaus F. Helm

Copyright (C) 2010 Nicole D. Riddle et al. This is an open access article distributed under the Creative Commons Attribution License, which permits unrestricted use, distribution, and reproduction in any medium, provided the original work is properly cited.

Context. Leiomyosarcomas are rare malignant smooth muscle tumors that may arise in any organ or tissue that contains smooth muscle, commonly within the gastrointestinal tract. They are most often found in the stomach, large and small intestines, and retroperitoneum. Primary pancreatic leiomyosarcoma is extremely rare, and to the best of our knowledge only 30 cases have been reported in the world literature since 1951. Our case represents the first to have a clear origin from the main pancreatic duct. Case Report. This case was diagnosed in a large, tertiary care center in Tampa, Florida. Pertinent information was obtained from chart review and interdepartmental collaboration. A mass in the tail of the pancreas was identified with large pleomorphic and spindle-shaped cells. Immunohistochemistry for vimentin, smooth muscle actin, and desmin was positive. All remaining immunohistochemical markers performed were negative. The tumor clearly originated from the pancreatic duct wall, filled and expanded the duct lumen, and was covered with a layer of benign biliary epithelium. Conclusion. Leiomyosarcoma of the pancreas is an extremely rare malignancy with few reported cases in the literature. The prognosis is poor, and treatment consists of alleviating symptoms and pain management. To our knowledge, this represents the first reported case demonstrating clear origin of a leiomyosarcoma from the pancreatic duct.

\section{Introduction}

Leiomyosarcomas are rare malignant tumors of smooth muscle origin that may arise in any organ or tissue that contains smooth muscle and comprise less than $1 \%$ of all cancers and 2\%-9\% of sarcomas [1]. They are most commonly found in the stomach and small intestine and may also be commonly found in the large intestine, uterus, and retroperitoneum [1]. Primary pancreatic leiomyosarcoma is extremely rare and has seldomly been reported in the literature. Typically the prognosis is poor, and treatment consists of alleviating symptoms and managing discomfort with one or more modalities including surgery, radiation, and/or chemotherapy. This case shows a clear origination from the pancreatic duct.

\section{Case Report}

An 83-year-old woman presented with a 3-month history of left-sided abdominal pain and weight loss. Her history was pertinent for a total abdominal hysterectomy with bilateral salpingo-oophorectomy in 1963 for benign leiomyomas with dysmenorrhea, a cholecystectomy in 1978 for cholelithiasis, and a hernia repair in 1993. No mass lesion was identified on physical examination. Abdominal CT scan and MRI revealed an $8 \mathrm{~cm}$ mass within the tail of the pancreas with no evidence of invasion into adjacent structures. At this time the presumed diagnosis was pancreatic adenocarcinoma. Ultrasound-guided biopsy of the lesion was attempted but yielded no diagnostic tissue. A distal pancreatectomy with splenectomy was performed and revealed an intrapancreatic 


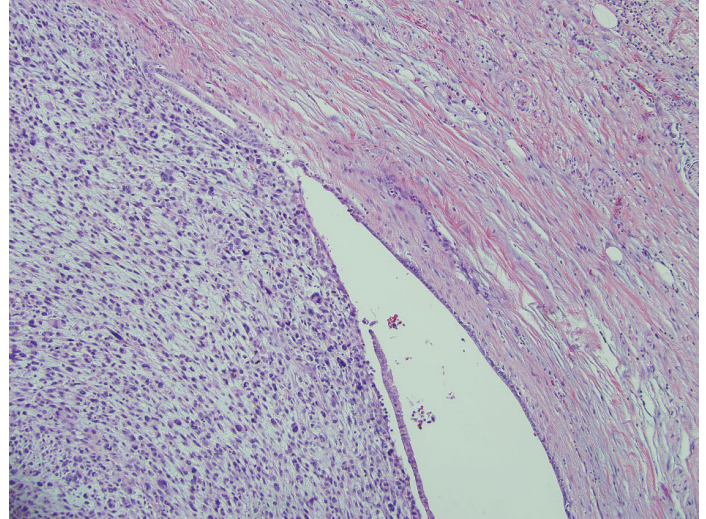

Figure 1: Low power view of the tumor showing the expansion of the duct wall with dilation of the lumen ( $\mathrm{H} \& \mathrm{E} 100 \mathrm{x})$.

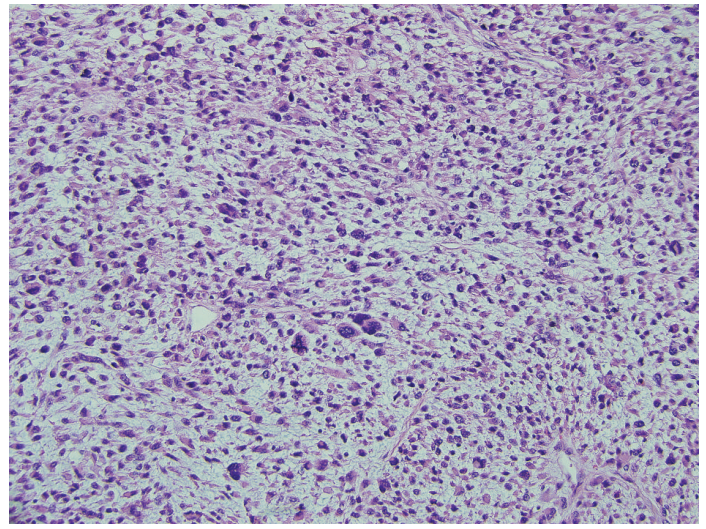

Figure 2: High power view showing highly pleomorphic cells and numerous/atypical mitosis ( $\mathrm{H} \& \mathrm{E} 400 \mathrm{x}$ ).

tan, nodular mass measuring $8.5 \times 7.0 \times 6.2 \mathrm{~cm}$ with focal hemorrhagic areas suggestive of necrosis. The margins were grossly free of tumor. Histological examination showed large pleomorphic and spindle-shaped cells, focal necrosis, and a mitotic count of $>20$ per 10 high power fields, with negative surgical margins (Figures 1 and 2). Multiple sections failed to demonstrate a malignant epithelial component. Immunohistochemical analysis showed tumor cells positive for smooth muscle actin (SMA), desmin, and vimentin and negative for other markers performed (pan cytokeratin, c-kit, CD34, and S-100) (Figures 3 and 4). There was a clear origination from the pancreatic duct wall with expansion of the lumen. Based on the histopathology and immunohistochemical profile, a diagnosis of leiomyosarcoma was rendered. The patient decided against further treatment and at 8 months was doing well with no apparent residual disease or metastasis.

\section{Discussion}

Primary pancreatic sarcomas of any type are rare although many have been reported in the literature including fibromyxoid sarcoma, follicular dendritic cell sarcoma,

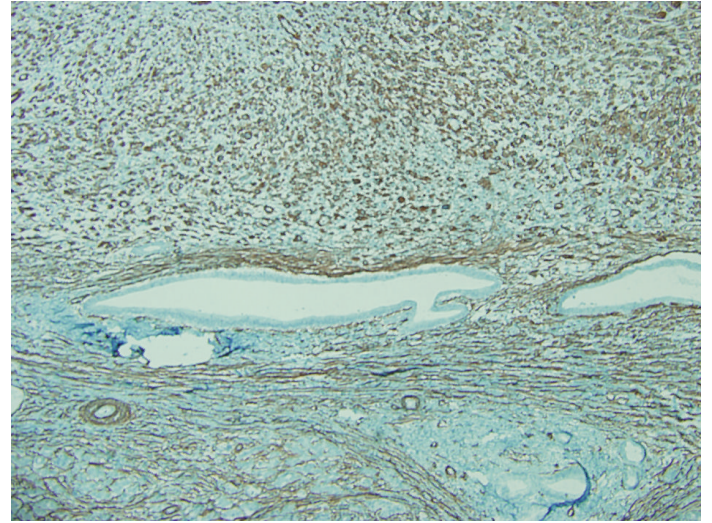

Figure 3: Smooth muscle actin immunohistochemical stain shows positive staining in the pleomorphic and spindle tumor cells, indicating smooth muscle origin of this lesion (100x).

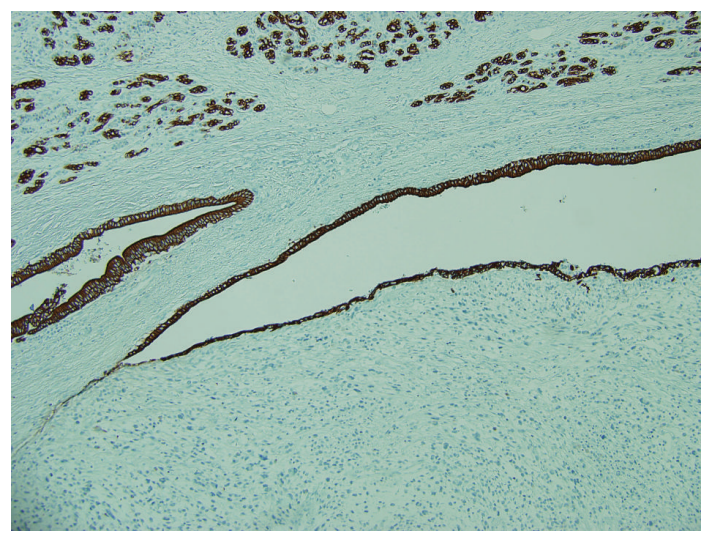

Figure 4: Pan-keratin, highlighting the residual ductal epithelium with no staining in tumor cells (100x).

Kaposi's sarcoma, leiomyosarcoma, fibrosarcoma, liposarcoma, angiosarcoma, and rhabdomyosarcoma [2-14]. Epidemiologic data derived from case reports suggests that most of the cases of primary pancreatic sarcoma occur in patients over 50 if not over 70 years of age, except for rhabdomyosarcoma which favors children and sometimes young adults [8]. It has been suggested that the pancreatic duct or blood vessel walls most likely serve as an origin for pancreatic leiomyosarcomas, a thought that is supported by their usual location within the body or tail [15]. Our case represents the first time clear origination from the pancreatic duct wall has been shown.

Leiomyosarcomas are malignant smooth muscle neoplasms that can arise in any anatomic location containing smooth muscle, most commonly the stomach, but can be found anywhere along the gastrointestinal tract, as well as the uterus and retroperitoneum. They have also been reported in the skin, bladder, ovaries, salivary glands, larynx, gallbladder, adrenal glands, broad ligament, diaphragm, breast, vulva, penis, scrotum and testis, and, of course, the pancreas [16-37]. Leiomyosarcomas are rare, comprising less than $1 \%$ of all cancers. A compilation of data on pancreatic 
leiomyosarcomas presented by Aihara et al. shows an age range of $14-80$ years for initial diagnosis of pancreatic leiomyosarcoma with a mean of 52.8 years and a median of 52.5 years [15]. Of the patients who died from pancreatic leiomyosarcoma, mean time to death was 11.5 months with a range of 5 days to 4 years [15]. These aggressive tumors tend to metastasize hematogenously, most commonly to the lung and less frequently the liver, brain, bone, spinal column, and skin $[21,31,38]$. On histopathological examination, malignancy is mainly determined by tumor necrosis, the number of mitoses (generally believed to be $\geq 2 / 10 \mathrm{HPF}$ ), atypical mitotic activity, and an infiltrative pattern. Most leiomyosarcomas are immunopositive for SMA, desmin, caldesmon, and vimentin.

\section{Conclusion}

Leiomyosarcoma of the pancreas is an extremely rare malignancy with few reported cases in the literature. The prognosis is poor, and treatment consists of surgical resection with chemotherapy and/or radiation for alleviating symptoms and pain management. To our knowledge, this represents the first reported case demonstrating clear origin of a leiomyosarcoma from the pancreatic duct.

\section{References}

[1] C. D. M. Fletcher, K. K. Unni, and F. Mertens, Eds., Pathology and Genetics of Tumours of Soft Tissue and Bone, World health Organization Classificaiton of Tumors, IARC Press, Lyon, France, 2002.

[2] T. E. Elliott, V. J. Albertazzi, and L. A. Danto, "Pancreatic liposarcoma: case report with review of retroperitoneal liposarcomas," Cancer, vol. 45, no. 7, pp. 1720-1723, 1980.

[3] D. Bastian, A. Ramaswamy, P. J. Barth, B. Gerdes, M. Ernst, and D. Bartsch, "Malignant fibrous histiocytoma of the pancreas: a case report with genetic analysis," Cancer, vol. 85, no. 11, pp. 2352-2358, 1999.

[4] T. Komatsu, S. Taira, O. Matsui, T. Takashima, M. Note, and H. Fujita, "A case of ruptured mesenchymal chondrosarcoma of the pancreas," Radiation Medicine, vol. 17, no. 3, pp. 239241, 1999.

[5] D. M. Liu, R. B. Jeffrey Jr., and R. E. Mindelzun, "Malignant fibrous histiocytoma presenting as cystic pancreatic mass," Abdominal Imaging, vol. 24, no. 3, pp. 299-300, 1999.

[6] M. Menges and H. W. Pees, "Kaposi's sarcoma of the pancreas mimicking pancreatic cancer in an HIV- infected patient: clinical diagnosis by detection of HHV 8 in bile and complete remission following antiviral and cytostatic therapy with paclitaxel," International Journal of Pancreatology, vol. 26, no. 3, pp. 193-199, 1999.

[7] F. Ravandi-Kashani, E. Estey, J. Cortes, L. J. Medeiros, and F. J. Giles, "Granulocytic sarcoma of the pancreas: a report of two cases and literature review," Clinical and Laboratory Haematology, vol. 21, no. 3, pp. 219-224, 1999.

[8] S. Dimicoli, P. Feugier, P. Delaby, et al., "Granulocyte sarcoma of the pancreas without extra-pancreatic involvement," Presse Medicale, vol. 31, no. 22, pp. 1024-1026, 2002.

[9] I. Yasuda, S. Adachi, S. Kasahara, et al., "Pancreatic rhabdomyosarcoma," Gastrointestinal Endoscopy, vol. 60, no. 3, pp. 433-434, 2004.
[10] S.-C. Shen, C.-C. Wu, K.-F. Ng, R.-C. Wu, H.-M. Chen, and T.C. Chen, "Follicular dendritic cell sarcoma mimicking giant cell carcinoma of the pancreas," Pathology International, vol. 56, no. 8, pp. 466-470, 2006.

[11] B.-G. Oh, Y. H. Han, B. H. Lee, et al., "Primary extraskeletal mesenchymal chondrosarcoma arising from the pancreas," Korean Journal of Radiology, vol. 8, no. 6, pp. 541-544, 2007.

[12] R. Colović, N. Grubor, M. Misev, M. Jovanović, and V. Radak, "Fibromyxoid sarcoma of the pancreas," Srpski Arhiv Za Celokupno Lekarstvo, vol. 136, no. 3-4, pp. 158-161, 2008.

[13] A. K. Seth, P. Argani, and K. A. Campbell, "Angiosarcoma of the pancreas: discussion of a rare epithelioid neoplasm," Pancreas, vol. 37, no. 2, pp. 230-231, 2008.

[14] R.-S. Yu, J.-W. Wang, Y. Chen, W.-H. Ding, X.-F. Xu, and L.R. Chen, "A case of primary malignant fibrous histiocytoma of the pancreas: CT and MRI findings," World Journal of Gastroenterology, vol. 14, no. 18, pp. 2942-2945, 2008.

[15] H. Aihara, Y. J. Kawamura, N. Toyama, Y. Mori, F. Konishi, and S. Yamada, "A small leiomyosarcoma of the pancreas treated by local excision,” $H P B$, vol. 4, no. 3, pp. 145-148, 2002.

[16] S. Lott, A. Lopez-Beltran, R. Montironi, G. T. MacLennan, and L. Cheng, "Soft tissue tumors of the urinary bladder. Part II: malignant neoplasms," Human Pathology, vol. 38, no. 7, pp. 963-977, 2007.

[17] M. Piana, R. Martínez Mansur, J. Codone, et al., "Penile leiomyosarcoma: case report and bibliographic review," Archivos Espanoles de Urologia, vol. 59, no. 7, pp. 728-731, 2006.

[18] S. Taşkin, E. A. Taşkin, N. Üzüm, Ö. Ataoğlu, and F. Ortaç, "Primary ovarian leiomyosarcoma: a review of the clinical and immunohistochemical features of the rare tumor," Obstetrical and Gynecological Survey, vol. 62, no. 7, pp. 480-486, 2007.

[19] N. M. Annest, S. J. Grekin, M. S. Stone, and M. J. Messingham, "Cutaneous leiomyosarcoma: a tumor of the head and neck," Dermatologic Surgery, vol. 33, no. 5, pp. 628-633, 2007.

[20] M. B. A. Garcia Torrelles, J. Rubio Tortosa, I. Sanchez Sanchis, et al., "Cutaneous leiomyosarcoma: a case report," Archivos Españoles de Urología, vol. 59, no. 9, pp. 908-910, 2006.

[21] M. R. Diz Rodríguez, M. Virseda Chamorro, J. R. Ramirez García, E. Merino Royo, A. Moreno Reyes, and P. Paños Lozano, "Scrotal leiomyosarcoma with bone metastasis," Actas Urologicas Españolas, vol. 30, no. 6, pp. 638-640, 2006.

[22] A. Sethi, S. Mrig, D. Sethi, A. K. Mandal, and A. K. Agarwal, "Parotid gland leiomyosarcoma in a child: an extremely unusual neoplasm," Oral Surgery, Oral Medicine, Oral Pathology, Oral Radiology and Endodontology, vol. 102, no. 1, pp. 8284, 2006.

[23] I. C. Aguilar, V. A. Benavente, M. R. Pow-Sang, et al., "Leiomyosarcoma of the renal vein: case report and review of the literature," Urologic Oncology, vol. 23, no. 1, pp. 22-26, 2005.

[24] B. Belaabidia, S. Sellami, R. Benelkhayat, H. Elattar, and A. Elidrissi Dafali, "Léiomyosarcoma of the diaphragm: a case report and review of the literature," Cancer Radiother, vol. 10, no. 3, pp. 137-141, 2006.

[25] L. Bernardos, A. Trujillo, A. Huete, et al., "Primary leiomyosarcoma of the gallbladder," Revista Espanola de Enfermedades Digestivas, vol. 96, no. 4, pp. 286-287, 2004.

[26] T. Bucci, F. Longo, G. M. Mangone, M. E. Errico, and L. Califano, "Leiomyosarcoma of the submandibular gland. Report of a case and review of the literature," International Journal of Oral and Maxillofacial Surgery, vol. 34, no. 6, pp. 690-692, 2005. 
[27] B. K. Canales, S. J. Lukasewycz, J. C. Manivel, and J. L. Pryor, "Postradiotherapy intratesticular leiomyosarcoma," Urology, vol. 66, no. 3, p. 657, 2005.

[28] N. Efstathopoulos, J. Lazarettos, V. Nikolaou, and E. Chronopoulos, "Inflammatory leiomyosarcoma of the ankle: a case report and review of the literature," Journal of Foot and Ankle Surgery, vol. 45, no. 2, pp. 127-130, 2006.

[29] T. John, D. Portenier, B. Auster, D. Mehregan, A. Drelichman, and A. Telmos, "Leiomyosarcoma of scrotum-case report and review of literature," Urology, vol. 67, no. 2, article 424, pp. e13-e15, 2006.

[30] T. Kato, S. Sakamoto, T. Kobayashi, et al., "Primary adrenal leiomyosarcoma with inferior vena cava thrombosis," International Journal of Clinical Oncology, vol. 9, no. 3, pp. 189-192, 2004.

[31] A. Munakata, K. Asano, T. Hatayama, K. Itoh, S. Suzuki, and H. Ohkuma, "Leiomyosarcoma of the uterus metastatic to brain," Neurological Surgery, vol. 34, no. 4, pp. 409-413, 2006.

[32] R. Murialdo, A. Usset, T. Guido, F. Carli, F. Boccardo, and D. Amoroso, "Leiomyosarcoma of the broad ligament: a case report and review of literature," International Journal of Gynecological Cancer, vol. 15, no. 6, pp. 1226-1229, 2005.

[33] C. E. Skoulakis, P. Stavroulaki, P. Moschotzopoulos, M. Paxinos, A. Fericean, and D. E. Valagiannis, "Laryngeal leiomyosarcoma: a case report and review of the literature," European Archives of Oto-Rhino-Laryngology, vol. 263, no. 10, pp. 929-934, 2006.

[34] V. K. Stafyla, J. M. Gauvin, and D. R. Farley, "A 53-year-old woman with a leiomyosarcoma of the breast," Current Surgery, vol. 61, no. 6, pp. 572-575, 2004.

[35] V. B. Thapar, R. R. Satoskar, G. M. Kanjan, and A. S. Chaudhary, "Leiomyosarcoma of the inferior vena cava: a case report and review of literature," International Surgery, vol. 90, no. 5, pp. 262-265, 2005.

[36] W. A. A. Tjalma and C. G. A. Colpaert, "Myxoid leiomyosarcoma of the vulva," Gynecologic Oncology, vol. 96, no. 2, pp. 548-551, 2005.

[37] A. Trabelsi, E. Mutijima, A. El Hossini Soua, et al., "Primary myxoid leiomyosarcoma of the ovary. A case report with review of the literature," Tunisie Medicale, vol. 83, no. 5, pp. 288-291, 2005.

[38] T. Vandergriff, R. A. Krathen, and I. Orengo, "Cutaneous metastasis of leiomyosarcoma," Dermatologic Surgery, vol. 33, no. 5, pp. 634-637, 2007. 


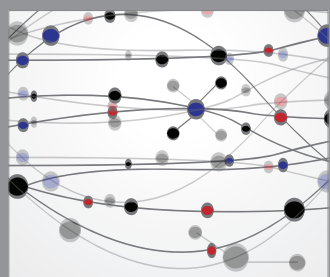

The Scientific World Journal
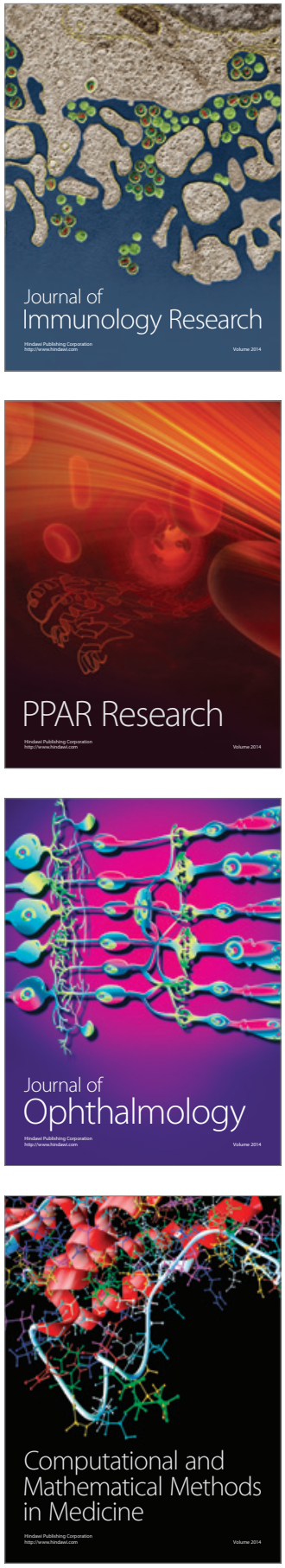

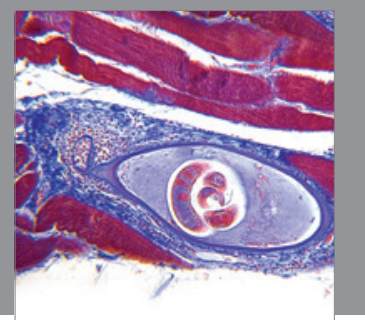

Gastroenterology

Research and Practice
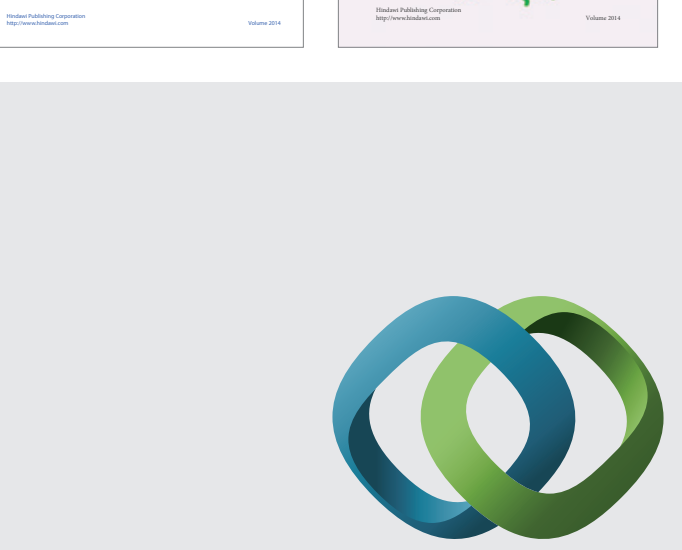

\section{Hindawi}

Submit your manuscripts at

http://www.hindawi.com
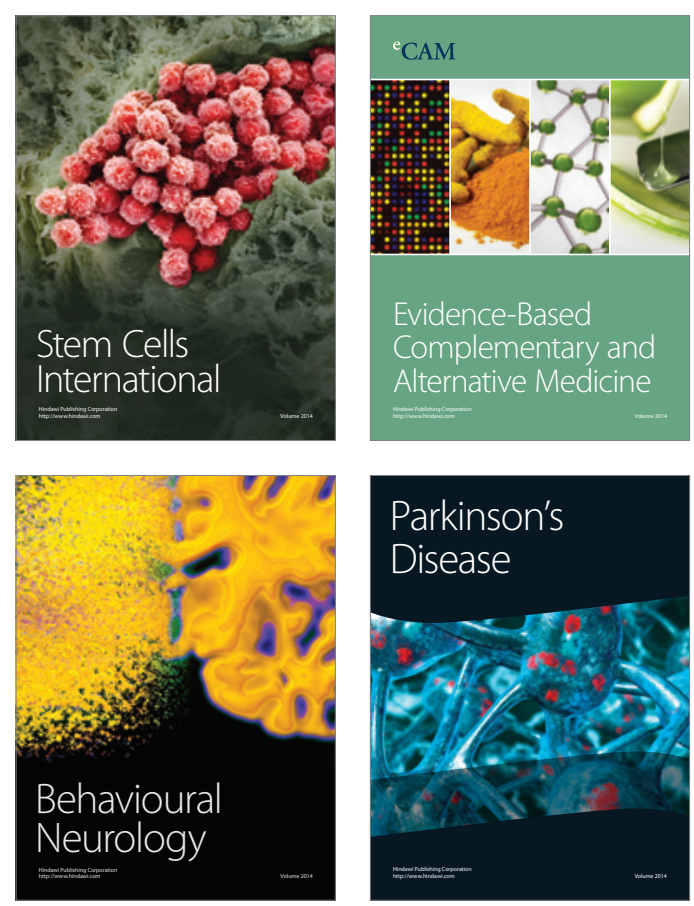

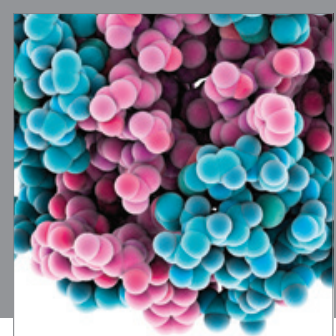

Journal of
Diabetes Research

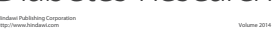

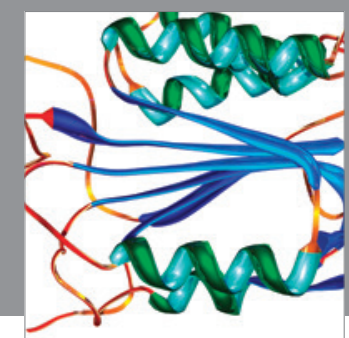

Disease Markers
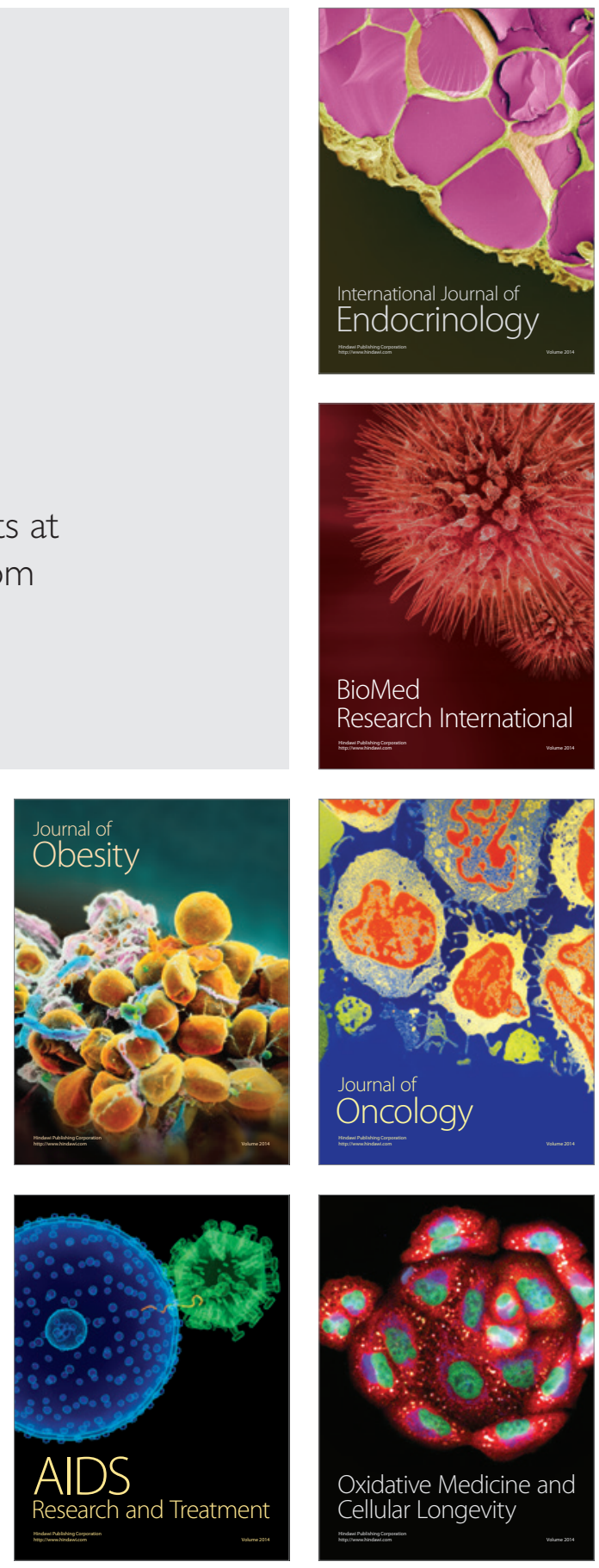